\title{
DEVELOPMENT OF WATER QUALITY PARAMETER RETRIEVAL ALGORITHMS FOR ESTIMATING TOTAL SUSPENDED SOLIDS AND CHLOROPHYLL-A CONCENTRATION USING LANDSAT-8 IMAGERY AT POTERAN ISLAND WATER
}

\author{
N. Lailia ${ }^{\text {a F. Arafah }}{ }^{\mathrm{a}}$, L.M. Jaelania*, L. Subehie ${ }^{\mathrm{e}}$, A. Pamungkas ${ }^{\mathrm{b}}$, E.S. Koenhardono ${ }^{\mathrm{c}}$, A. Sulisetyono ${ }^{\mathrm{d}}$
}

a $\quad$ b

Dept. of Geomatics Engineering, Faculty of Civil Engineering and Planning; Dept. of Urban and Regional Planning, Faculty of Civil Engineering and Planning; ${ }^{c}$ Dept. of Marine Engineering, Faculty of Marine Technology; ${ }^{d}$ Dept. of Naval Architecture and Shipbuilding Engineering, Faculty of Marine Technology, Institut Teknologi Sepuluh Nopember, Surabaya, 60111, Indonesia. Email: nurahida11@mhs.geodesy.its.ac.id, feny13@mhs.geodesy.its.ac.id, 1mjaelani@geodesy.its.ac.id, adjie@urplan.its.ac.id,

\section{eddy-koen@its.ac.id, sulisea@na.its.ac.id}

Research Centre for Limnology, Indonesian Institute of Sciences, Cibinong Science Centre, 16911, Indonesia. Email: luki@limnologi.lipi.go.id KEYWORDS : Total Suspended Solids, Chlorophyll-A, Landsat-8, Poteran Island Water.

\begin{abstract}
:
The Landsat- 8 satellite imagery is now highly developed compares to the former of Landsat projects. Both land and water area are possibly mapped using this satellite sensor. Considerable approaches have been made to obtain a more accurate method for extracting the information of water area from the images. It is difficult to generate an accurate water quality information from Landsat images by using some existing algorithm provided by researchers. Even though, those algorithms have been validated in some water area, but the dynamic changes and the specific characteristics of each area make it necessary to get them evaluated and validated over another water area. This paper aims to make a new algorithm by correlating the measured and estimated TSS and Chla concentration. We collected in-situ remote sensing reflectance, TSS and Chl-a concentration in 9 stations surrounding the Poteran islands as well as Landsat 8 data on the same acquisition time of April 22, 2015. The regression model for estimating TSS produced high accuracy with determination coefficient $\left(R^{2}\right)$, NMAE and RMSE of $0.709 ; 9.67 \%$ and $1.705 \mathrm{~g} / \mathrm{m}^{3}$ respectively. Whereas, Chla retrieval algorithm produced $R^{2}$ of 0.579 ; NMAE of $10.40 \%$ and RMSE of $51.946 \mathrm{mg} / \mathrm{m}^{3}$. By implementing these algorithms to Landsat 8 image, the estimated water quality parameters over Poteran island water ranged from 9.480 to $15.801 \mathrm{~g} / \mathrm{m}^{3}$ and 238.546 to

$346.627 \mathrm{mg} / \mathrm{m}^{3}$ for TSS and Chl-a respectively.

Jordan 2005; Bhatti et al. 2010; Bailey and Werdell 2006), those algorithms have been developed and validated using in situ data that was collected in some specific water area. Since, the dynamic changes and the specific characteristics of water make them unsuitable for another water area such as in Indonesia.
\end{abstract}

\section{INTRODUCTION}

To support the sustainable development of water environment, a routine water quality monitoring is a critical requirement. By considering the spatial and temporal heterogeneity of water bodies, extracting water information by remote sensing techniques can be more effective approach than a direct field measurement (Liu, Islam, and Gao 2003)

The estimation of water quality parameters such as the concentration of TSS (Total suspended sediments) and Chl-a (Chlorophyll-a) from satellite images is strongly depend on the accuracy of atmospheric correction and water quality parameter retrievals algorithms (Ruddick, Ovidio, and Rijkeboer 2000; Sathyendranath, Prieur, and Morel 1987; Yang et al. 2011; Jaelani et al. 2013; Jaelani, Matsushita, et al. 2015).

Numerous researches have been conducted to develop and validate both atmospheric correction algorithm and water quality parameter retrieval algorithm. Since the development of first algorithm needs a comprehensive study and rigorous spectral data over study area (Jaelani, Matsushita, et al. 2015; Jaelani et al. 2013), this paper only focus on the second issue. Even though, there were many existing water quality parameter retrieval algorithms to estimate TSS and Chl-a concentration of water from satellite images (Sathyendranath and Platt 1989; Gons, Auer, and Effler 2008; Sathyendranath, Prieur, and Morel 1987; Nas et al. 2009; Dall'Olmo et al. 2005; Han and
Consequently, The objective of the present study was to develop more accurate TSS and Chl-a concentration retrieval algorithms for Landsat 8 images at Poteran island water of Indonesia using in situ spectra, TSS and Chl-a concentration.

\section{METHODS}

To develop a new algorithm for TSS and Chl-a concentration retrieval algorithms, we collected concurrent in situ and Landsat 8 data from Poteran island water on April 22, 2015. The water area is located in Sumenep Sub-district, southeastearn Madura Island. The in situ data were measured and collected at 9 stations as shown in Fig. 1 and Table 1. For each station, we collected remote sensing reflectance (Rrs)

(were measured using a FieldSpec HandHeld spectroradiometer in the range of $325-1075 \mathrm{~nm}$ at $1 \mathrm{~nm}$ intervals), and water samples that analyzed in laboratory furthermore. TSS concentration was gravimetrically extracted from water sample, whereas Chl-a concentration was analyzed using spectrophotometer at four wavelengths $(750,663,645$, and 630 $\mathrm{nm})$. 


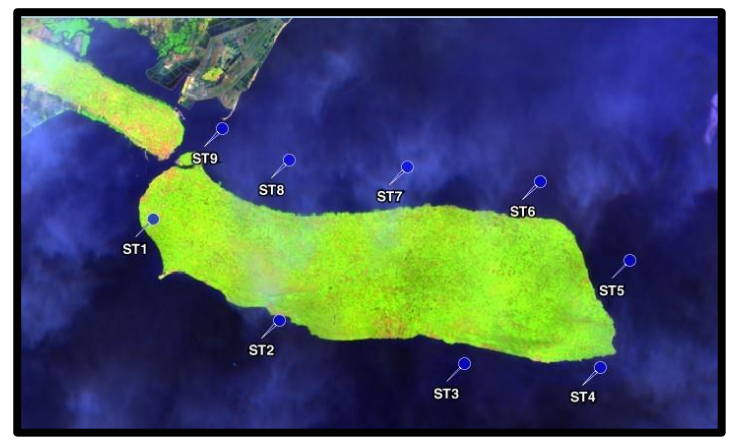

Figure 1. Field Measurements Locations at Poteran Island Water

\begin{tabular}{|c|c|c|c|c|c|c|c|}
\hline \multirow[b]{2}{*}{ Station } & \multicolumn{2}{|c|}{ Water Quality } & \multicolumn{5}{|c|}{$\begin{array}{l}\operatorname{Rrs}(s r \\
\left.{ }^{1}\right)\end{array}$} \\
\hline & $\underset{\left(\mathbf{m g} / \mathbf{m}^{3}\right)}{\text { Chl-a }}$ & $\underset{\left(\mathbf{g} / \mathbf{m}^{3}\right)}{\text { TSS }}$ & $\begin{array}{l}440 \\
\mathrm{~nm}\end{array}$ & $\begin{array}{l}480 \\
\mathrm{~nm}\end{array}$ & $\begin{array}{l}560 \\
\mathrm{~nm}\end{array}$ & $\begin{array}{l}655 \\
\mathrm{~nm}\end{array}$ & $\begin{array}{l}865 \\
\mathrm{~nm}\end{array}$ \\
\hline St.1 & 278 & 14 & 0.018 & 0.019 & 0.019 & 0.010 & 0.003 \\
\hline St.2 & 286 & 13 & $\mathrm{n} / \mathrm{a}$ & $\mathrm{n} / \mathrm{a}$ & $\mathrm{n} / \mathrm{a}$ & $\mathrm{n} / \mathrm{a}$ & $\mathrm{n} / \mathrm{a}$ \\
\hline St.3 & 298 & 13 & 0.043 & 0.046 & 0.043 & 0.024 & 0.017 \\
\hline St.4 & 280 & 15 & 0.043 & 0.045 & 0.047 & 0.030 & 0.019 \\
\hline St.5 & 254 & 14 & 0.046 & 0.045 & 0.042 & 0.026 & 0.018 \\
\hline St.6 & 386 & 16 & 0.063 & 0.065 & 0.067 & 0.057 & 0.046 \\
\hline St.7 & 459 & 18 & 0.035 & 0.039 & 0.046 & 0.030 & 0.012 \\
\hline St. 8 & 327 & 17 & $\mathrm{n} / \mathrm{a}$ & $\mathrm{n} / \mathrm{a}$ & $\mathrm{n} / \mathrm{a}$ & $\mathrm{n} / \mathrm{a}$ & n/a \\
\hline St.9 & 332 & 16 & 0.016 & 0.023 & 0.027 & 0.015 & 0.001 \\
\hline
\end{tabular}

Table 1. Field measurements data

A regression model between every single band (band 1-5) or band-ratio of Landsat with in situ TSS and Chl-a concentration were assessed to find the most strongest correlation.

In addition, we collected Landsat 8 image (path/row $=117 / 65$ ) at the same time of field campaign time. This data was used to map Chl-a and TSS concentration spatially.

Since, the Landsat- 8 data (level 1T) was stored in digital number $(D N)$. It has to be radiometrically converted to the topof-atmosphere radiance $\left(L_{T O A}\right)$ by using following formula.

$$
L_{\lambda}=M_{\lambda} x Q_{\text {Cal }}+A_{\lambda}
$$

Where:

$$
\begin{array}{ll}
L_{\lambda} & =\text { TOA spectral radiance } \\
M_{\lambda} & =\text { Band-specific multiplicative rescaling factor } \\
Q_{C a l} & =\text { Digital number } \\
A_{\lambda} & =\text { Band-specific additive scaling factor }
\end{array}
$$

After obtaining the radiance value, the next step was atmospheric correction that will automatically convert the topof-atmosphere radiance value $(L T O A)$ to bottom-ofatmosphere reflectance $\left(\rho_{B O A}\right)$. Then, the BOA Reflectance was converted to Reflectance remote-sensing $(R r s)$ value.

To correct the image from atmospheric effect, we used

Second Simulation of a Satellite Signal in the Solar Spectrum-Vector (6SV) algorithm (Vermote et al. 1997) that calculated atmospheric-corrected reflectance for image from three parameters as follow:

$$
\begin{gathered}
y=\left(x_{a} \times L_{\lambda}\right)-x_{b} \\
\operatorname{acr}=\frac{y}{1+\left(x_{c} \times y\right)} \\
\operatorname{Rrs}(\lambda)=\operatorname{acr} / \pi
\end{gathered}
$$

Where :

acr = Atmospherically corrected reflectance

$L \lambda=$ TOA Radiance measured data $\operatorname{Rrs}(\lambda)=$ Reflectance remote-sensing $x a, x b, x c=$ Atmospherical correction parameters coefficient.

The image was now stored in $\operatorname{Rrs}(\lambda)$ value. This value was required in order to estimate water quality parameters (TSS and Chl-a concentration) based on the developed water quality retrieval algorithms in previous step.

To assess the accuracy of the developed algorithms, a formula of RMSE (Root Mean Square Error) and NMAE (Normalized Mean Absolute Error) were used.

$$
\begin{array}{r}
R M S E=\sqrt{\frac{\sum_{i=1}^{n}\left(X_{\text {est } i}-X_{\text {meas }}\right)^{2}}{N}} \\
\operatorname{NMAE}(\%)=\frac{1}{N} \sum_{i=1}^{N}\left|\frac{x_{\text {est } i, i}-x_{\text {meas }, i}}{x_{\text {meas }}}\right| \times 100
\end{array}
$$

$X_{\text {est } i}$ is the value of TSS and chlorophyll-a estimated by using the algorithms. $X_{\text {meas }}$ is the value of measured TSS and chlorophyll-a. $N$ is the number of samples. The determination coefficient $\left(R^{2}\right)$ was also calculated to assess the relationship between estimated and measured concentrations.

\section{RESULTS}

\subsection{The relationship of the measured and estimated $\operatorname{Rrs}(\lambda)$ values}

There were two data collections of the remote sensing reflectance $(\operatorname{Rrs}(\lambda))$ values, one was obtained from field measurements (measured-Rrs $(\lambda)$ ) and the second was estimated from the Landsat- 8 image by performing radiometric calibration and atmospheric correction (estimated- $\operatorname{Rrs}(\lambda)$ ). These data were presented in Fig. 2 and 3. 


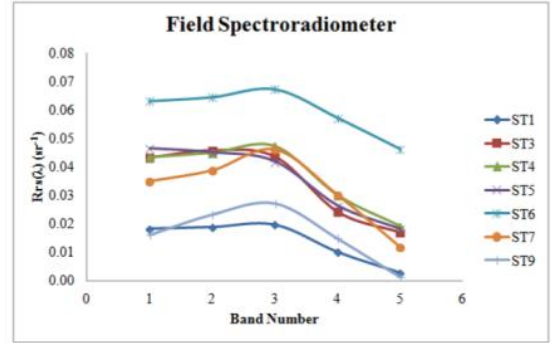

Figure 2. Measured-Rrs $(\lambda)$

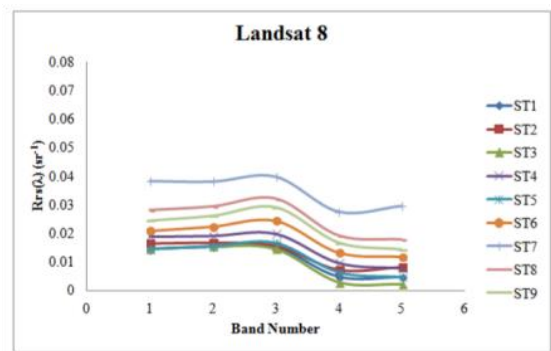

Figure 3. Estimated-Rrs $(\lambda)$

In Figure 2, even though the measured-Rrs $(\lambda)$ were measured in 9 stations, only 7 data have been successfully recorded. The data in Station 2 and 8 were missing due to unfavorable weather during field campaign.

Figure 2 and 3 showed that the measured-Rrs $(\lambda)$ values were higher than those of estimated one. The measured-Rrs $(\lambda)$ from band 1 to 5 ranged between 0.001 to 0.067 , while the estimated one from 0.002 to 0.039 . These fact indicate estimated-Rrs $(\lambda)$ was suffered by inaccurate atmospheric correction (aerosol scattering overestimation). The same case was found in atmospheric correction by $6 \mathrm{SV}$ as reported by

Jaelani, Setiawan, and Matsushita (2015)

\subsection{Developed-Algorithm for Estimating TSS}

The TSS algorithm was developed by correlating in situ TSS concentration with in situ measured-Rrs $(\lambda)$ using regression model following the works of Han and Jaelani (Han and Jordan 2005; Jaelani, Setiawan, et al. 2015). In this algorithm development, the in situ TSS concentration was used as dependent variable and the measured-Rrs $(\lambda)$ for independent variable. The common model used as follow:

$$
y=a x+b .
$$

The value of $x$ was the modified form of $\operatorname{Rrs}(\lambda)$ (single band or band-ratio), whereas the $y$ value was the TSS concentration. Various regression model then were calculated over the measured-Rrs $(\lambda)$ values to obtain the estimated-TSS concentration. The regression model for TSS and the estimatedTSS concentration were shown in Table 2 and 3.

Some acceptable determination coefficient $\left(R^{2}\right)$ which value higher than 0.5 showed in the ratio of $\operatorname{Rrs}(\lambda 2) / \operatorname{Rrs}(\lambda 3)$, $\operatorname{Rrs}(\lambda 2) / \operatorname{Rrs}(\lambda 4)$ and $\operatorname{Rrs}(\lambda 1) / \operatorname{Rrs}(\lambda 4)$. The highest $R^{2}$ showed in the ratio of $\operatorname{Rrs}(\lambda 2) / \operatorname{Rrs}(\lambda 3)$ which value of 0.795 , while the lowest $R^{2}$ showed in the ration of $\operatorname{Rrs}(\lambda 1) / \operatorname{Rrs}(\lambda 5)$, which was 0.001 . This model then used to calculate the estimated-TSS concentration.

To assess the performance of estimated-TSS that was calculated based on combination of three regression models and three independent variables, we compared that value to the measured one as shown in Table 3. The calculated RMSE, NMAE and $R$ were presented in Table 4. RMSE and NMAE were used to assess the accuracy of the data between the measured and estimated TSS. While $R^{2}$ was used for assessing its correlation. According to Jaelani, Setiawan, and Matsushita (2015), the minimum requirement of $N M A E$ value to extract the water quality parameters from remote sensing data is below of $30 \%$. The $R^{2}$ values ranged between 0.496 to 0.709 , with the highest accuracy produced by regression model using ratio band of $\operatorname{Rrs}(\lambda 2) / \operatorname{Rrs}(\lambda 4)$ as an independent variable (Fig. 4). 
This algorithm then be applied to the Landsat- 8 image to obtain the estimated TSS values. Those estimated values with the highest $R^{2}$ then be validated to the measured one as shown in Fig. 5.

\begin{tabular}{|c|c|c|c|c|c|}
\hline Regression model & $\operatorname{Rrs}\left(\lambda_{1}\right)$ & $\operatorname{Rrs}\left(\lambda_{2}\right)$ & $\operatorname{Rrs}\left(\lambda_{3}\right)$ & $\operatorname{Rrs}\left(\lambda_{4}\right)$ & $\operatorname{Rrs}\left(\lambda_{5}\right)$ \\
\hline$T S S=a\left(x_{i}\right)+b$ & 0.001 & 0.003 & 0.075 & 0.107 & 0.006 \\
\hline$T S S=a^{*} \log \left(x_{i}\right)+b$ & 0.002 & 0.004 & 0.069 & 0.104 & 0.001 \\
\hline Regression model & $\operatorname{Rrs}\left(\lambda_{4}\right) / \operatorname{Rrs}\left(\lambda_{5}\right)$ & $\begin{array}{l}\operatorname{Rrs}\left(\lambda_{3}\right) / \\
\operatorname{Rrs}\left(\lambda_{4}\right)\end{array}$ & $\operatorname{Rrs}\left(\lambda_{3}\right) / \operatorname{Rrs}\left(\lambda_{5}\right)$ & $\operatorname{Rrs}\left(\lambda_{2}\right) / \operatorname{Rrs}\left(\lambda_{3}\right)$ & $\operatorname{Rrs}\left(\lambda_{2}\right) / \operatorname{Rrs}\left(\lambda_{4}\right)$ \\
\hline$T S S=a\left(x_{i} / x_{j}\right)+b$ & 0.056 & 0.204 & 0.038 & 0.722 & 0.664 \\
\hline$T S S=a * \log \left(x_{i} / x_{j}\right)+b$ & 0.072 & 0.192 & 0.025 & 0.733 & 0.628 \\
\hline $\begin{array}{l}T S S=a^{*}\left(\log \left(x_{i}\right) / \log \left(x_{j}\right)\right)+ \\
b\end{array}$ & 0.141 & 0.202 & 0.041 & 0.794 & 0.696 \\
\hline Regression model & $\operatorname{Rrs}\left(\lambda_{2}\right) / \operatorname{Rrs}\left(\lambda_{5}\right)$ & $\operatorname{Rrs}\left(\lambda_{1}\right) / \operatorname{Rrs}\left(\lambda_{2}\right)$ & $\operatorname{Rrs}\left(\lambda_{1}\right) / \operatorname{Rrs}\left(\lambda_{3}\right)$ & $\operatorname{Rrs}\left(\lambda_{1}\right) / \operatorname{Rrs}\left(\lambda_{4}\right)$ & $\operatorname{Rrs}\left(\lambda_{1}\right) / \operatorname{Rrs}\left(\lambda_{5}\right)$ \\
\hline$T S S=a\left(x_{i} / x_{j}\right)+b$ & 0.025 & 0.156 & 0.429 & 0.746 & 0.011 \\
\hline$T S S=a^{*} \log \left(x_{i} / x_{j}\right)+b$ & 0.006 & 0.142 & 0.389 & 0.736 & 0.001 \\
\hline $\begin{array}{l}\operatorname{TSS}=a^{*}\left(\log \left(x_{i}\right) / \log \left(x_{j}\right)\right)+ \\
b\end{array}$ & 0.002 & 0.163 & 0.465 & 0.738 & 0.002 \\
\hline
\end{tabular}

Table 2. Regression model combination for TSS with $\mathrm{R}^{2}$

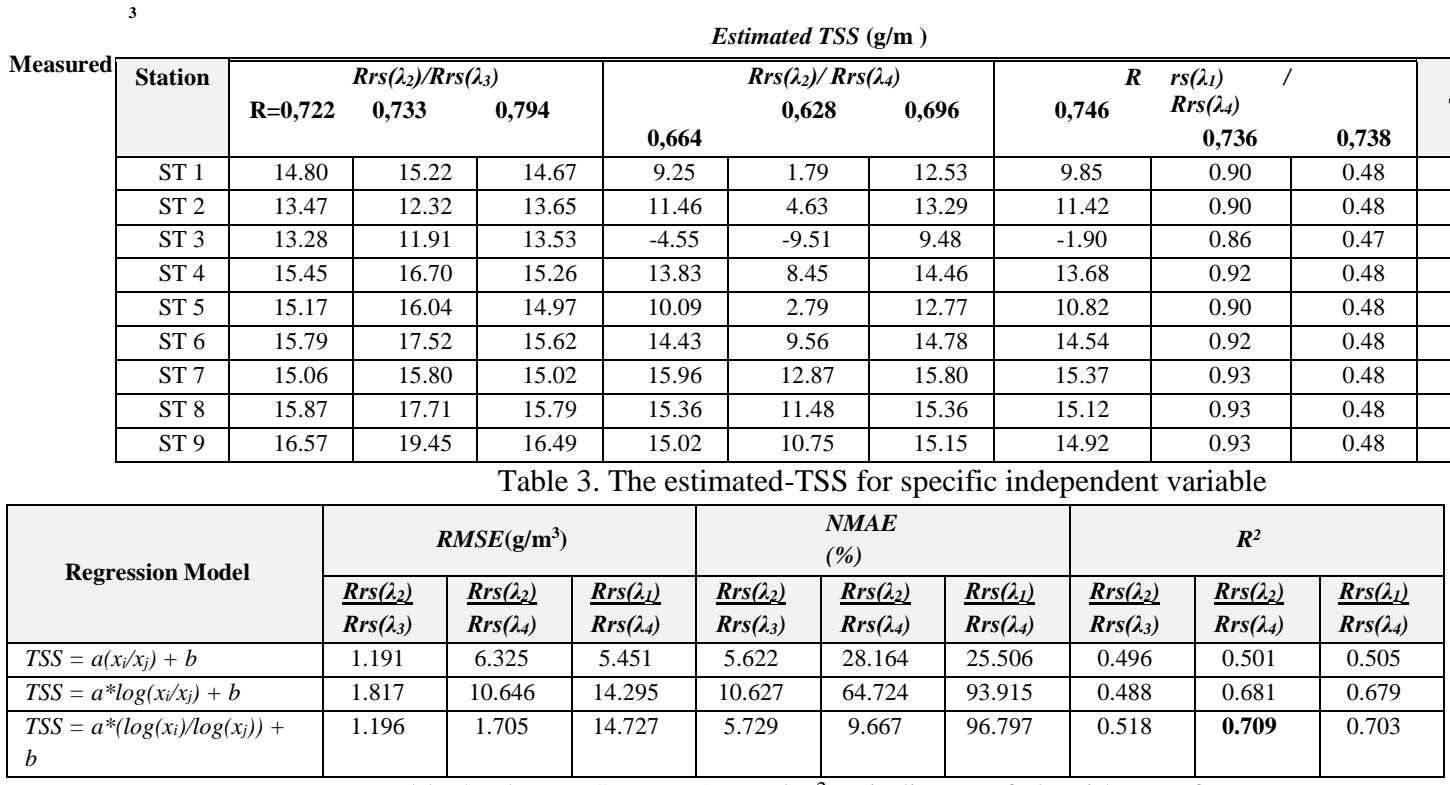

Table 4. The RMSE, NMAE and $R^{2}$ as indicator of algorithm performance 


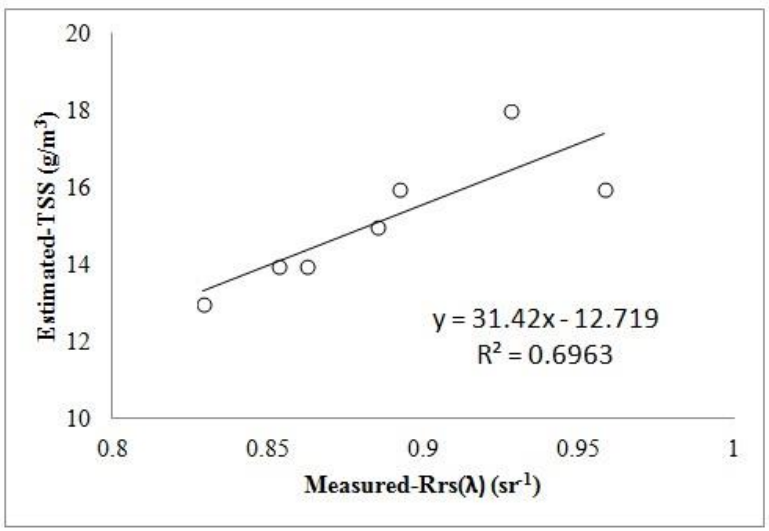

Figure 4.Regression model for TSS with independent variable of band-ratio of $\operatorname{Rrs}(\lambda 2) / \operatorname{Rrs}(\lambda 4)$

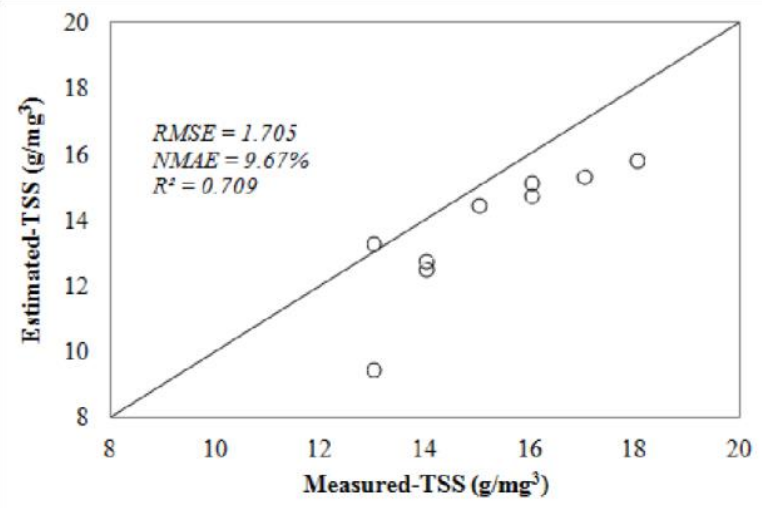

Figure 5. Estimated vs. Measured TSS

Considering the results showed in Fig. 5, the algorithm used to estimates the TSS values over the Landsat- 8 image can now be arranged following the formula below :

$$
\begin{aligned}
& y=31.42 x-12.719 \\
& \text { TSS }=a\left(\frac{\log x_{i}}{\log x_{j}}\right)-b
\end{aligned}
$$

Then,

$$
T S S=31.42\left(\frac{\log R r S_{2}}{\log R r s_{4}}\right)-12.719
$$

The estimated-TSS concentration from Landsat-8 images was presented as well as the measured concentration in Table

5.

\begin{tabular}{ccc}
\hline Station & Estimated-TSS $\left(\mathrm{g} / \mathrm{m}^{3}\right)$ & Measured-TSS $\left(\mathrm{g} / \mathrm{m}^{3}\right)$ \\
\hline ST1 & 12.526 & 14 \\
ST2 & 13.294 & 13 \\
ST3 & 9.480 & 13 \\
ST4 & 14.464 & 15 \\
ST5 & 12.769 & 14 \\
ST6 & 14.779 & 16 \\
ST7 & 15.801 & 18 \\
ST8 & 15.363 & 17 \\
ST9 & 15.152 & 16 \\
\hline
\end{tabular}

Table 5. The value of estimated and measured-TSS 


\subsection{Developed Algorithm for Estimating Chlorophyll-a}

The Chlorophyll-a estimation from spectra data follow the same step of TSS. The modeling was made using regression models with single band and band-ratio of Landsat were

presented in Table 6 .

\begin{tabular}{|c|c|c|c|c|c|}
\hline \multirow[b]{2}{*}{ Regression model } & \multicolumn{5}{|c|}{$R^{2}$} \\
\hline & $\operatorname{Rrs}\left(\lambda_{1}\right)$ & $\operatorname{Rrs}\left(\lambda_{2}\right)$ & $\operatorname{Rrs}\left(\lambda_{3}\right)$ & $\operatorname{Rrs}\left(\lambda_{4}\right)$ & $\operatorname{Rrs}\left(\lambda_{5}\right)$ \\
\hline$C h l=a x+b$ & 0.017 & 0.048 & 0.172 & 0.108 & 0.052 \\
\hline$C h l=a x^{2}-b x+c$ & 0.036 & 0.059 & 0.182 & 0.199 & 0.111 \\
\hline$C h l=a^{*} \log (x)+b$ & 0.014 & 0.046 & 0.151 & 0.183 & 0.019 \\
\hline$C h l=a^{*}(\log (x))^{2}-b * \log (x)+c$ & 0.032 & 0.046 & 0.151 & 0.184 & 0.051 \\
\hline \multirow[b]{2}{*}{ Regression model } & \multicolumn{5}{|c|}{$R^{2}$} \\
\hline & $\operatorname{Rrs}\left(\lambda_{4}\right) / \operatorname{Rrs}\left(\lambda_{5}\right)$ & $\operatorname{Rrs}\left(\lambda_{3}\right) / \operatorname{Rrs}\left(\lambda_{4}\right)$ & $\operatorname{Rrs}\left(\lambda_{3}\right) / \operatorname{Rrs}\left(\lambda_{5}\right)$ & $\operatorname{Rrs}\left(\lambda_{2}\right) / \operatorname{Rrs}\left(\lambda_{3}\right)$ & $\operatorname{Rrs}\left(\lambda_{2}\right) / \operatorname{Rrs}\left(\lambda_{4}\right)$ \\
\hline$C h l=a *(x i / x j)+b$ & 0.002 & 0.231 & 0 & 0.491 & 0.564 \\
\hline$C h l=a^{*}(x i / x j) 2-b^{*}(x i / x j)+c$ & 0.006 & 0.232 & 0.009 & 0.524 & 0.593 \\
\hline$C h l=a * \log (x i / x j)+b$ & 0.005 & 0.231 & 0.001 & 0.500 & 0.576 \\
\hline$C h l=a^{*}(\log (x i / x j))^{2}-b^{*}(\log (x i / x j))+c$ & 0.021 & 0.232 & 0.007 & 0.529 & 0.578 \\
\hline$C h l=a^{*}(\log (x i) / \log (x j))+b$ & 0.031 & 0.219 & 0.001 & 0.572 & 0.605 \\
\hline $\begin{array}{l}C h l=a^{*}(\log (x i) / \log (x j))^{2}-b^{*}(\log (x i) / \log (x j))+ \\
c\end{array}$ & 0.056 & 0.236 & 0.030 & 0.634 & 0.615 \\
\hline \multirow[b]{2}{*}{ Regression model } & \multicolumn{5}{|c|}{$R^{2}$} \\
\hline & $\begin{array}{l}\operatorname{Rrs}\left(\lambda_{2}\right) / \\
\operatorname{Rrs}\left(\lambda_{5}\right)\end{array}$ & $\begin{array}{l}\operatorname{Rrs}\left(\lambda_{1}\right) / \\
\operatorname{Rrs}\left(\lambda_{2}\right)\end{array}$ & $\begin{array}{l}\operatorname{Rrs}\left(\lambda_{1}\right) / \\
\operatorname{Rrs}\left(\lambda_{3}\right) \\
\end{array}$ & $\begin{array}{l}\operatorname{Rrs}\left(\lambda_{1}\right) / \\
\operatorname{Rrs}\left(\lambda_{4}\right) \\
\end{array}$ & $\begin{array}{l}\operatorname{Rrs}\left(\lambda_{1}\right) / \\
\operatorname{Rrs}\left(\lambda_{5}\right)\end{array}$ \\
\hline$C h l=a(x i / x j)+b$ & 0.001 & 0.076 & 0.269 & 0.566 & 0.007 \\
\hline$C h l=a^{*}(x i / x j)^{2}-b^{*}(x i / x j)+c$ & 0.047 & 0.419 & 0.429 & 0.584 & 0.073 \\
\hline$C h l=a * \log (x i / x j)+b$ & 0.009 & 0.060 & 0.224 & 0.573 & 0.023 \\
\hline$C h l=a^{*}(\log (x i / x j))^{2}-b^{*}(\log (x i / x j))+c$ & 0.048 & 0.444 & 0.496 & 0.575 & 0.077 \\
\hline$C h l=a^{*}(\log (x i) / \log (x j))+b$ & 0.015 & 0.083 & 0.295 & 0.566 & 0.049 \\
\hline $\begin{array}{l}C h l=a^{*}(\log (x i) / \log (x j))^{2}-b^{*}(\log (x i) / \log (x j))+ \\
c\end{array}$ & 0.074 & 0.453 & 0.499 & 0.569 & 0.106 \\
\hline
\end{tabular}

Table 6. Regression model combination for Chl-a with $R^{2}$

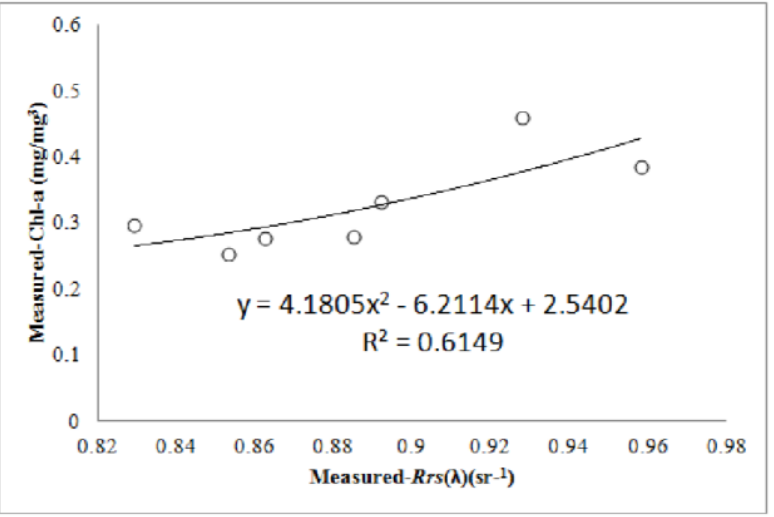

Figure 6. Regression model for Chl-a with independent variable of band-ratio of $\operatorname{Rrs}(\lambda 2) / \operatorname{Rrs}(\lambda 4)$

\begin{tabular}{ccc}
\hline Station & $\begin{array}{c}\text { Estimated Chl-a } \\
\left(\mathbf{m g} / \mathbf{m}^{\mathbf{3}}\right)\end{array}$ & $\begin{array}{c}\text { Measured Chl-a } \\
\left(\mathbf{m g} / \mathbf{m}^{\mathbf{3}}\right)\end{array}$ \\
\hline St.1 & 248.8729 & 278 \\
St.2 & 263.228 & 286 \\
St.3 & 238.546 & 298 \\
St.4 & 295.538 & 280 \\
St.5 & 252.5938 & 254 \\
St.6 & 306.2124 & 386 \\
St.7 & 346.6274 & 459 \\
St.8 & 328.1409 & 327
\end{tabular}


St.9

319.9305

Table 7. The value of estimated and measured-Chl-a

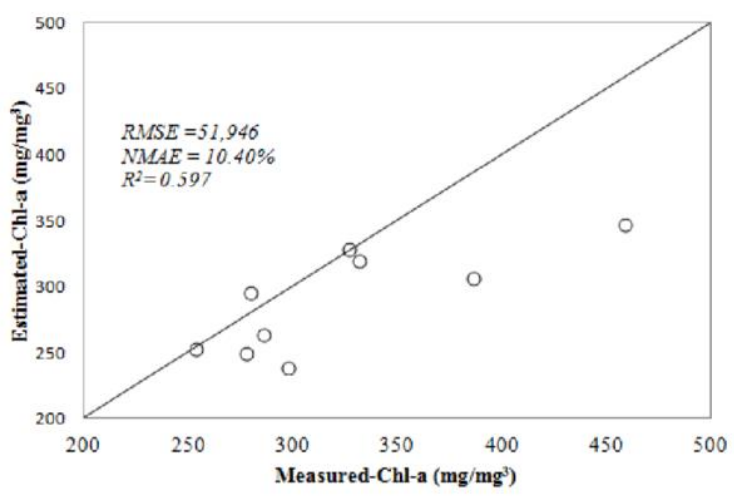

Figure 7. Estimated vs. Measured Chl-a

Figure 6 showed the regression model for Chl-a concentration estimation that was built using band-ratio of $\operatorname{Rrs}(\lambda 2) / \operatorname{Rrs}(\lambda 4)$ an independent variable. This model had a highest correlation between measured-Chl and remote sensing reflectance with $R^{2}$ of 0.615 . The summary of developed algorithm as follow:

$$
\begin{array}{r}
y=4180.5 x^{2}-6211.4 x+2540.2 \\
\text { Chl }-a=a\left(\frac{\log x_{i}}{\log x_{j}}\right)^{2}-b\left(\frac{\log x_{i}}{\log x_{j}}\right)+c \text { (12) } \\
\text { Chl }-a=4180.5\left(\frac{\log R r s_{2}}{\log R r s_{4}}\right)^{2}-6211.4\left(\frac{\log R r s_{2}}{\log R r s_{4}}\right)+2540.2(13)
\end{array}
$$

Therefore, the above algorithm was used to calculate the estimated-Chl-a concentration from Landsat-8 image reflectance. The calculation results of estimated concentration of chlorophyll-a in 9 stations shown in Table 7 and Fig. 7.

\section{CONCLUSION}

We developed a new algorithm for estimating TSS and Chl-a concentration that was applicable in small part of Indonesia water. For that purposes, We collected in-situ remote sensing reflectance, TSS and Chl-a concentration in 9 stations surrounding the Poteran islands as well as Landsat 8 data on the same acquisition time of April 22, 2015.

$$
\begin{array}{lll}
\text { The } & \text { regression model for estimating } \\
\text { TSS } & (T S S= \\
& \left.31.420\left(\frac{\log R r S_{2}}{\log R r s_{4}}\right)-12.71\right) \text { produced high accuracy with }
\end{array}
$$
determination coefficient $\left(R^{2}\right)$, NMAE and RMSE of 0.709 ; $9.67 \%$; and $1.705 \mathrm{~g} / \mathrm{m}^{3}$ respectively. Whereas, Chl-a retrieval algorithm

$$
\left(C h l-a=4180.5\left(\frac{\log R r s_{2}}{\log R r s_{4}}\right)^{2}-6211.4\left(\frac{\log R r s_{2}}{\log R r s_{4}}\right)+2540.2\right)
$$

produced $R^{2}$ of 0.579 ; NMAE of $10.40 \%$; and RMSE of 51.946 $\mathrm{mg} / \mathrm{m}^{3}$. By implementing these algorithms to Landsat 8 image, the estimated water quality parameters over Poteran island water ranged from 9.480 to $15.801 \mathrm{~g} / \mathrm{m}^{3}$ and 238.546 to 346.627 $\mathrm{mg} / \mathrm{m}^{3}$ for TSS and Chl-a respectively.

In general, the developed algorithm for estimating TSS and Chla concentration produced acceptable accuracy (NMAE $<30 \%$ ), thus extracting water information from satellite images using these algorithms are applicable. Whereas, the low correlation between measured and estimated-Chl-a concentration $\left(R^{2}=0.597\right)$ was caused not only by performance of the developed-Chl-a estimation algorithm but also the accuracy of atmospheric correction algorithm by $6 \mathrm{SV}$.

To assess the implementation in wider area, in short future, we are going to validate the developed algorithms using in situ data collected in different water area in Indonesia.

\section{ACKNOWLEDGEMENTS}

This research is a part of Sustainable Island Development Initiatives (SIDI) Program, a collaborative research in small island development between Indonesia and Germany.

\section{REFERENCES}

Bailey, Sean W., and P. Jeremy Werdell. 2006. "A MultiSensor Approach for the on-Orbit Validation of Ocean Color Satellite Data Products." Remote Sensing of Environment 102 (1-2): 12-23. doi:10.1016/j.rse.2006.01.015.

http://linkinghub.elsevier.com/retrieve/pii/S003442570 6000472.

Bhatti, Asif M, Donald Rundquist, John Schalles, Mark Steele, and Masataka Takagi. 2010. "QUALITATIVE ASSESSMENT OF INLAND AND COASTAL WATERS BY USING." In Remote Sensing Science, Spatial Information, XXXVIII:415-20.

Dall'Olmo, Giorgio, Anatoly A. Gitelson, Donald C. Rundquist, Bryan Leavitt, Tadd Barrow, and John C. Holz. 2005. "Assessing the Potential of SeaWiFS and MODIS for Estimating Chlorophyll Concentration in Turbid Productive Waters Using Red and near-Infrared Bands." Remote Sensing of Environment 96 (2): 17687. doi:10.1016/j.rse.2005.02.007.

http://linkinghub.elsevier.com/retrieve/pii/S003442570 5000854 .

Gons, Herman J., Martin T. Auer, and Steven W. Effler. 2008. "MERIS Satellite Chlorophyll Mapping of Oligotrophic and Eutrophic Waters in the Laurentian Great Lakes." Remote Sensing of Environment 112 (11): 4098-4106. doi:10.1016/j.rse.2007.06.029. http://linkinghub.elsevier.com/retrieve/pii/S003442570 8002083 .

Han, Luoheng, and Karen J. Jordan. 2005. "Estimating and Mapping Chlorophyll- a Concentration in Pensacola Bay, Florida Using Landsat ETM+ Data." International Journal of Remote Sensing 26 (23): 5245-54. doi:10.1080/01431160500219182. http://www.tandfonline.com/doi/abs/10.1080/0143116 0500219182. 
Jaelani, Lalu Muhamad, Bunkei Matsushita, Wei Yang, and Takehiko Fukushima. 2013. "Evaluation of Four MERIS Atmospheric Correction Algorithms in Lake Kasumigaura, Japan." International Journal of Remote Sensing 34 (24). Taylor \& Francis: 8967-85. doi:10.1080/01431161.2013.860660. http://dx.doi.org/10.1080/01431161.2013.860660.

2015. "An Improved Atmospheric Correction Algorithm for Applying MERIS Data to Very Turbid Inland Waters." International Journal of Applied Earth Observation and Geoinformation 39 (July). Elsevier B.V.: 128-41. doi:10.1016/j.jag.2015.03.004. http://dx.doi.org/10.1016/j.jag.2015.03.004.

Jaelani, Lalu Muhamad, Fajar Setiawan, and Bunkei Matsushita. 2015. "Uji Akurasi Produk ReflektanPermukaan Landsat Menggunakan Data In Situ Di

Danau Kasumigaura , Jepang.” In Pertemuan Ilmiah Tahunan Masyarakat Penginderaan Jauh Indonesia, 9-16. Bogor: MAPIN. doi:10.13140/RG.2.1.4002.8003.

Jaelani, Lalu Muhamad, Fajar Setiawan, Hendro Wibowo, and Apip. 2015. "Pemetaan Distribusi Spasial Konsentrasi Klorofil-A Dengan Landsat 8 Di Danau

Matano Dan Danau Towuti, Sulawesi Selatan.” In Pertemuan Ilmiah Tahunan Masyarakat Penginderaan Jauh Indonesia, 1-8. Bogor: MAPIN. doi:10.13140/RG.2.1.1905.6484.

Liu, Yansui, Md Anisul Islam, and Jay Gao. 2003. "Quantification of Shallow Water Quality Parameters by Means of Remote Sensing." Progress in Physical Geography 27 (1): 24-43. doi:10.1191/0309133303pp357ra. http://ppg.sagepub.com/cgi/doi/10.1191/0309133303p p357ra.

Nas, Bilgehan, Hakan Karabork, Semih Ekercin, and Ali Berktay. 2009. "Mapping Chlorophyll-a through inSitu Measurements and Terra ASTER Satellite Data." Environmental Monitoring and Assessment 157 (1-4): 375-82. doi:10.1007/s10661-008-0542-9. http://www.ncbi.nlm.nih.gov/pubmed/18821023.

Ruddick, Kevin George, Fabrice Ovidio, and Machteld Rijkeboer. 2000. "Atmospheric Correction of SeaWiFS Imagery for Turbid Coastal and Inland Waters." Applied Optics 39 (6): 897-912. http://www.opticsinfobase.org/abstract.cfm?URI=ao396-897.

Sathyendranath, S, and T Platt. 1989. "Remote Sensing of Ocean Chlorophyll: Consequence of Nonuniform Pigment Profile." Applied Optics 28 (3): 490-95. http://www.ncbi.nlm.nih.gov/pubmed/20548508.

Sathyendranath, S., L. Prieur, and A. Morel. 1987. “An

Evaluation of the Problems of Chlorophyll Retrieval from Ocean Colour, for Case 2 Waters." Advances in Space Research 7 (2): 27-30. doi:10.1016/02731177(87)90160-8. http://linkinghub.elsevier.com/retrieve/pii/0273117787 901608

Vermote, E.F., D. Tanre, J.L. Deuze, M. Herman, and J.-J. Morcette. 1997. "Second Simulation of the Satellite Signal in the Solar Spectrum, 6S: An Overview." IEEE Transactions on Geoscience and Remote Sensing 35 (3): 675-86. doi:10.1109/36.581987. http://ieeexplore.ieee.org/lpdocs/epic03/wrapper.htm?a rnumber $=581987$

Yang, Wei, Bunkei Matsushita, Jin Chen, and Takehiko Fukushima. 2011. "Estimating Constituent Concentrations in Case II Waters from MERIS Satellite Data by Semi-Analytical Model Optimizing and Lookup Tables." Remote Sensing of Environment 115 (5). Elsevier Inc.: 1247-59. doi:10.1016/j.rse.2011.01.007. http://linkinghub.elsevier.com/retrieve/pii/S003442571 1000204 